\title{
Bone morphogenetic proteins in development and progression of breast cancer and therapeutic potential (Review)
}

\author{
LIN YE, SIVAN M. BOKOBZA and WEN G. JIANG \\ Metastasis and Angiogenesis Research Group, Department of Surgery, \\ Cardiff University School of Medicine, Heath Park, Cardiff CF14 4XN, UK
}

Received July 13, 2009; Accepted August 19, 2009

DOI: 10.3892/ijmm_00000269

\begin{abstract}
Bone morphogenetic proteins (BMPs) belong to the TGF- $ß$ superfamily, which plays important roles in foetal and postnatal development and also maintains the homeostasis of various tissues and organs. Due to the critical role played by BMPs in bone formation and bone turnover, the implication of these molecules in bone metastasis has been intensively studied over the past decade. BMPs have been implicated in the development and progression of solid tumours, particularly the disease-specific bone metastasis. In breast cancer, a tumour type which most commonly metastasizes to bones, aberrations of both BMP expression and their signalling have been recently demonstrated. These aberrations have certain correlations with the development and progression of the disease. Recent in vitro studies have also demonstrated that BMPs can regulate a range of biological functions of breast cancer cells. Targeting BMPs or BMP signalling may provide novel therapeutic approaches for breast cancer. In the current review, we discuss the present knowledge on BMP abnormalities and their implication in the development and progression of breast cancer, particularly in the disease-specific bone metastasis.
\end{abstract}

\section{Contents}

1. Introduction

2. BMPs and tumour biology of breast cancer cells

3. Crosstalk between BMPs and estrogen signalling

4. The expression pattern of BMPs and BMP receptors in mammary gland and primary mammary tumours

5. BMPs and bone metastasis from breast cancer

6. Perspectives and therapeutic potential

Correspondence to: Dr Lin Ye, Metastasis and Angiogenesis Research Group, Department of Surgery, Cardiff University School of Medicine, Heath Park, Cardiff CF14 4XN, UK

E-mail: yel@cf.ac.uk

Key words: bone morphogenetic protein, breast cancer, bone metastasis, tumour biology

\section{Introduction}

Bone morphogenetic proteins (BMPs) are members of the TGF-ß superfamily, which participates in the development and homeostasis of diverse tissues and organs through regulating cellular differentiation, proliferation, apoptosis and motility. BMPs exert their effects through a heteromeric receptor complex, which comprises of two types of serine-threonine kinase transmembrane receptors. The Type-I receptors include Activin receptor-like kinase-1 (ALK-1), BMP receptor type IA (BMPR-IA, also known as ALK-3), BMP receptor type IB (BMPR-IB, or so-called ALK-6), ALK-4, ALK-5 and activin A receptor type I (ActRI). The Type-II receptors include BMP receptor type II (BMPR-II), activin A receptor type IIA (ActRIIA) and activin A receptor type IIB (ActRIIB). Upon binding to BMP ligands, the Type-II receptors then phosphorylate the glycine-serine (GS) domain of Type-I receptors. This leads to the recruitment of the pathway-restricted Smads (R-Smads, Smads1, 5 and 8) to the complex. The intracellular signaling complex of R-Smads is then translocated into the nucleus after binding with Smad-4, which leads to the regulation of BMP responsive genes. This pathway is known as the Smad-dependent pathway, in which Smad-6 and -7 act as inhibitory regulators to the signalling. The other pathway is known as the Smad-independent pathway, in which the mitogen-activated protein kinase (MAPK) pathway and the RAS pathway, may be involved (1).

BMPs are key factors in regulating bone formation and bone turnover and have been recently shown to play a pivotal role in tumour development, progression and bone metastasis (1). Breast cancer is the most common cancer in females in the UK and the USA and is the second leading cause of death from cancer. Its leading metastatic site is bone. The major bone lesion in breast cancer is osteolytic, which leads to bone pain, fractures, spine cord compression and hypercalcaemia. These morbidities severely impact the quality of life of the patients. The attention to BMPs and their role in breast cancer has increased as substantial progress has been made in this area. The present review summarises the current knowledge on the roles played by BMPs in breast cancer and their therapeutic potential.

\section{BMPs and tumour biology of breast cancer cells}

The roles of BMPs in the biology of breast cancer cells have been intensively investigated over the past decade. It is now 
known that BMPs are extensively involved in the regulation of cellular functions of breast cancer cells, ranging from cell growth and death, cell migration, invasion and epithelialmesenchymal transition (EMT).

Cell cycle and proliferation. BMPs are able to regulate the growth of breast cancer cells. However, the nature of cell response is influenced by the individual BMP, namely, with some BMPs having an inhibitory effect on proliferation of breast cancer cells, while others show a reverse effect (Fig. 1A). For example, BMP-2 and BMP-6 inhibit the proliferation of breast cancer cells $(2,3)$. On the other hand, some BMPs may indirectly promote the proliferation of breast cancer cells, such as BMP-4 which has a synergetic effect on the proliferation of breast cancer cells induced by fibroblast growth factor (FGF), epidermal growth factor (EGF) and hepatocyte growth factor (HGF) (4). This contrasting effect on proliferation of breast cancer cells was clearly demonstrated in a recently published study, where BMP-7 promoted proliferation of MDA-MB-231 and BT-474 cells, but showed an inhibitory effect on the other breast cancer cell lines tested (5).

BMPs can also co-regulate the growth of breast cancer cells induced by non-cytokine agents. For example, BMP-2 inhibits estrodiol-induced proliferation of breast cancer cells, via up-regulation of cyclin kinase inhibitor, p21 which in turn inhibits the estradiol-induced cyclin D1-associated kinase activity (6). The up-regulation of p21 by BMP-2 can also prevent EGF-induced proliferation of breast cancer cells (MDA-MB-231) (7). BMP-2 has a direct anti-proliferative effect on tumour cells at a very high concentration $(1 \mu \mathrm{g} / \mathrm{ml})$ in vitro (8). It is interesting to note that the regulation of $\mathrm{p} 21$ expression by BMP-2 was mediated by Type-I receptors, Smad-1 and Smad-4. In MDA-MB-468, which only expresses Smad-1, BMP-2 fails to induce p21 and inhibits cellular proliferation (9). BMP-6 inhibits proliferation and induces cell cycle arrest at G0/G1 stage in oestrogeninsensitive breast cancer cells (MDA-MB-231) (2).

To the same BMP protein, different breast cancer cell lines may have a different response. For example, MDA-MB-231, an ER-negative tumour cell line, responds to recombinant human BMP-2 with a greatly reduced proliferation, in comparison to the ER-positive MCF-7 cells (3). This suggests that the oestrogen receptor (ER) status has a bearing on the cell response to BMPs. This link is further strengthened by a study which revealed that BMP-6 and BMP-7 could inhibit oestrogen-induced mitosis of ER-positive breast cancer cells (10).

Apart from the ER status affecting the function of BMPs in breast cancer cells, the BMP receptors must be critical for this diversity due to their essential role in mediating BMP signalling. Recent studies have highlighted certain BMP receptors mediating contrasting effects in breast cancer cells. Overexpression of a domain-negative BMPR-II in breast cancer cells is able to interfere with the phosphorylation of Smad-1 by BMPR-II, leading to an arrest of the cancer cells at the G1 phase of the cell cycle. This suggests that coupling between BMPs and BMPR-II has a significant role in controlling the proliferation and survival of breast cancer cells (11). A domainnegative Type II TGF- $\beta$ receptor (dnTßRII) could eliminate the anti-proliferative effect of BMP-2 in breast cancer cells

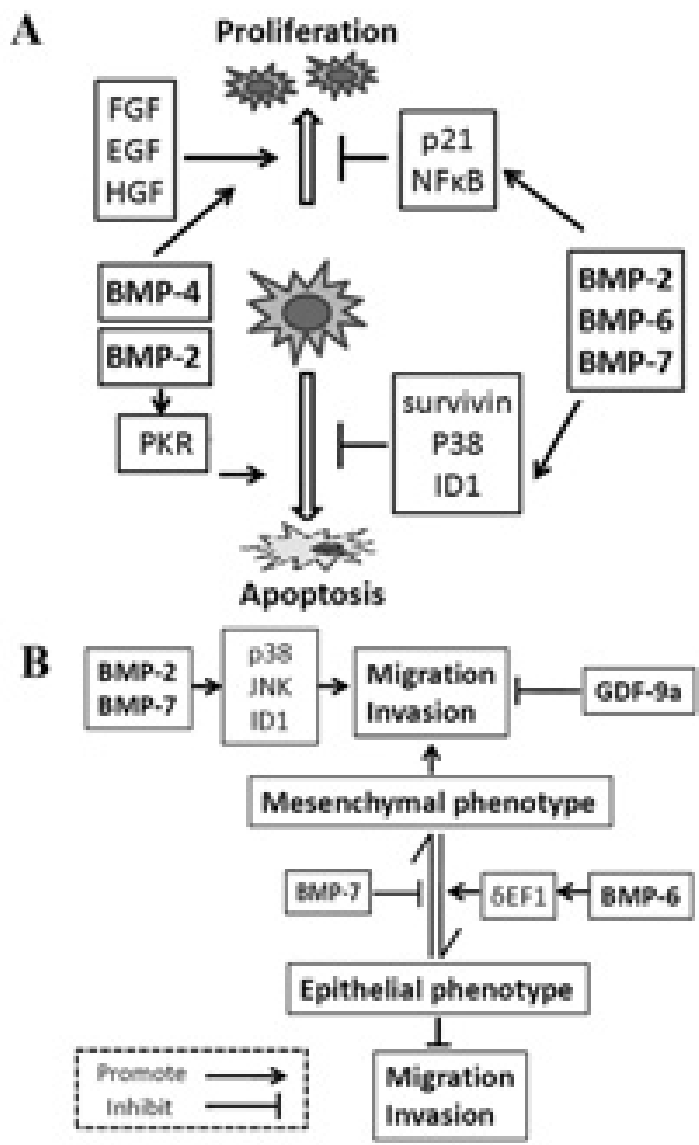

Figure 1. Influences on biological functions of breast cancer cells by BMPs. (A) BMPs regulate the proliferation and apoptosis of breast cancer cells. (B) The effect on cell motility and EMT of breast cancer cells by BMPs.

by preventing the phosphorylation of Smad-1 (12). One of the Type I receptors, BMPR-IA (ALK-3) has been recently shown to be involved in the activated Smad pathway which contributes to development and progression of breast cancer at primary and secondary sites (13). While BMPR-IA and BMPR-II play positive roles for BMP induced proliferation and aggressiveness in breast cancer cells, another Type I receptor, BMPR-IB has been indicated as a negative regulator (14).

Taken together, BMPs induce diverse effects in breast cancer cells due to the phenotypic profile of BMPs receptors, intracellular signalling molecules and regulatory factors.

Apoptosis. In addition to the pivotal role in the control of cell proliferation and growth, BMPs also play a profound role in regulating apoptosis of breast cancer cells (Fig. 1A). Most interestingly, BMPs can induce a biphasic effect on apoptosis in breast cancer cells depending on the type of BMPs, cell type and experimental circumstances. For example, under routine culture conditions, BMP-2 showed a pro-apoptotic effect in some breast cancer cells (MCF-7), in which the expression and function of apoptosis related genes, particularly protein kinase $\mathrm{R}(\mathrm{PKR})$ and subsequent activation of its substrate eIF $2 \alpha$ are regulated by the BMP (15). Under different experimental conditions, BMPs may play a contrasting role in regulation of apoptosis. For example, without supplement of serum, BMP-2 increases the resistance of breast cancer cells 
(MCF-7) to hypoxia-induced apoptosis, via the activation of both the MAPK pathway and ID-1 and suppression of caspase-3 $(16,17)$. The other example is BMP-6, which can inhibit the proliferation of breast cancer cells (MDA-MB-231). Under deprivation of serum, BMP-6 turns to protect these cancer cells from stress-induced apoptosis through upregulation of survivin via the Smad-dependent pathway and activation of p38 via the Smad-independent pathway and both contributed to the anti-apoptotic effect of BMP-6 (2).

Motility and invasiveness of tumour cells. Motility and invasiveness are essential capacities for cancer cells to disseminate and spread. The possible role BMPs play in regulation of cancer cell motility and invasiveness remains a topic of investigation (Fig. 1B). BMP-2 has shown a predominant effect in promoting the motility and invasiveness of breast cancer cells. For instance, BMP-2 promotes the aggressiveness of breast cancer cell (MCF-7) growth, in vitro and in vivo, in an oestrogen-independent manner (18). BMP-7 is also capable of promoting cell migration and invasion (5). These interesting observations certainly deserve additional research into the scope and the underlying mechanism(s) by which cell migration is affected by BMPs.

BMP-2 may contribute to the invasiveness of tumour cells via the induction of tenascin-W in the tumour surrounding stroma. Tenascin-W belongs to a family of extracellular matrix glycoproteins. It has been shown to be highly expressed in the stroma around breast carcinoma lesions and has been linked to the aggressiveness of tumour cells via its interaction with the $\alpha 8$ integrin. HC11 cells derived from normal mammary epithelium do not express $\alpha 8$ integrin and fail to cross tenascin-W-coated filters. However, 4T1 mammary carcinoma cells do express $\alpha 8$ integrin and their migration is stimulated by tenascin-W. BMP-2 can induce the expression of tenasin-W through the p38 MAPK and JNK pathway. This is in clear contrast to TGF- 1 1, which is a potent inducer of tenascin-C (19). Finally, up-regulation of ID-1 by BMP-2 may be another contributing factor in BMP-2 related aggressiveness of breast cancer cells (20).

On the other hand, some other BMPs may have an inhibitory effect on the aggressiveness of breast cancer cells. For example, forced expression of GDF-9a in breast cancer cells could reduce their invasiveness in vitro (21). BMP-2 has been demonstrated to inhibit collagenase- 3 in some bone cell types. Collagenase-3 (MMP-13) is expressed by hypertrophic chondrocytes, periosteal cells and osteoblasts during human fetal bone development. The expression of MMP-13 was enhanced by TGF- $\beta$, but was inhibited by BMP-2 (22). However, whether this is implicated in the invasiveness of breast cancer cells is still unknown.

Epithelial-mesenchymal transdifferentiation/transformation $(E M T)$. EMT regulated by BMPs has been implicated in foetal and postnatal development of different organs and tissues. EMT is also an important event during the development and progression of cancer. EMT not only causes a disruption of epithelial homeostasis which may lead to carcinogenesis, it can also transform the indolent tumour cells into a more aggressive colony, leading to metastasis. BMP-4 can subvert the ability of mammary epithelial cells to form polarized lumen-containing structures and also endows them with invasive properties (23). This supports the involvement of this BMP cytokine in the progression of breast cancer. In the bone metastasis-derived PC-3 prostate cancer cell line, BMP-7 has been shown to induce epithelial-mesenchymal transdifferentiation with classical changes in morphology and promote both motility and invasiveness in prostate cancer cells (24). However, in mammary epithelial cells (NMuMG), BMP-7 was not able to induce EMT whereas TGF- $\$ 1$ could (25). In contrast, some BMPs are able to reverse EMT and reduce the aggressive properties of tumour cells. For example, BMP-6 restores E-cadherin-mediated cell-to-cell adhesion and prevents breast cancer metastasis through the downregulation of $\delta E F 1$. Higher level of $\delta E F 1$ expression is associated with a more invasive phenotype of breast cancer cells (26). Another example is BMP-7, which is able to increase cytokeratin expression and decrease vimentin in breast cancer cells in vitro and in vivo, leading to an epithelial-like phenotype (27) (Fig. 1B).

BMPs and tumour related angiogenesis. Angiogenesis is an important event during the development and progression of both primary and secondary tumours. Current knowledge regarding the role of BMPs and angiogenesis is mainly from studies in prostate cancer and bone formation. It has been demonstrated that BMPs, including BMP-2, -4, -6, -7 and GDF5, are capable of inducing angiogenesis. This may be one of the ways by which these BMPs contribute to the process of bone formation $(28,29)$. Experimental evidence suggests that BMPs promote angiogenesis indirectly through upregulation of the expression of VEGF in both prostate cancer cells and osteoblasts $(30,31)$. The early stage of bone induction by rhBMP-2 can be blocked by the anti-angiogenic agent, TNP-470 (28). This evidence suggests that the control of angiogenesis by BMPs may be, to some extent, coupled with osteoblastic activity.

Presently, the understanding of the role of BMPs in angiogenesis in breast cancer is poor. There is very limited literature in this aspect, one study has reported that BMP-2 promotes tumour-related angiogenesis through stimulating p38 MAPK pathway and ID-1 (32). This is obviously a fertile area for explorers.

\section{Crosstalk between BMPs and estrogen signalling}

The involvement of oestrogen in the development and progression of breast cancer is well established. Prolonged exposure to oestrogen in circumstances such as early menarche, late menopause and nulliparity has been considered as high risk to developing breast carcinoma. The effect of oestrogen is largely mediated through two oestrogen receptors, ER- $\alpha$ (ESR1) and ER-B (ESR2). ER status is correlated with prognosis of patients with breast cancer and is thus a key indicator for selecting endocrine therapies. A possible relationship between BMP/BMP receptor signalling events and ER is an interesting topic. Some of the recent studies have shown some positive correlations.

First, it seems that oestrogen is able to regulate the expression of BMP and BMP receptors. Oestrogen can repress the expression of some BMP receptors, such as BMPR-IA, 
BMPR-IB, ACVR2A, and ACVR2B, but has no effect on the expression of ACVR1 and BMPR-II (10). In line with this observation, the expression of some BMPs and BMP receptors in breast cancer tissues has been shown to correlate with ER status. The expression of BMP-7 has been found to highly correlate with the expressing level of both estrogen receptor (ER) and progesterone receptor (33). Using enzyme restriction PCR (MSRE-PCR), as well as bisulfate sequencing (BSG), methylation of the human BMP-6 gene promoter was detected in MDA-MB-231; while in MCF-7 and T47D, the BMP-6 gene promoter remained demethylated. In 33 breast tumour specimens, promoter methylation of BMP- 6 was detected by methylation-specific PCR. Hypermethylation of BMP-6 was observed in ER-negative cases [16 of 16 cases (100\%)], while obviously lower methylation frequency were observed in ERpositive cases [3 of 17 cases (18\%)], indicating that BMP-6 promoter methylation status correlates with ER status in breast cancer (34). Different roles played by ER- $\alpha$ and ER- $\beta$ in the regulation of BMPs have been otherwise revealed in osteoblastlike cells. Anti-oestrogen reagent raloxifene could increase the activity of the BMP-4 promoter in U-2 OS osteoblast-like cells. ER- $\alpha$, but not ER- $\beta$, is thought to be indispensable for this effect on the BMP-4 promoter. However, ER- $\beta$ may synergetically enhance this activation of the BMP-4 promoter by raloxifene (35). The role played by ER- $\beta$ in the regulation of BMPs and BMP signalling by oestrogen in breast cancer cells remains unclear.

On the other hand, oestrogen and BMPs can influence each other's function through interaction between their receptor and downstream signalling. Oestrogen can interfere with the biological function of BMP-2 by inhibiting the activation of Smad, as a result of biochemical interaction between Smad and oestrogen receptor (ER) (36). BMP signalling molecules also have some influence on the signalling events of oestrogen via the interaction with ERs. Smad-4 is indispensible for the Smad-dependent signalling by BMPs and other TGF- $\beta$ family members. It has also been shown that an association between Smad-4 and ER- $\alpha$ prevents the transcriptional regulation mediated by ER- $\alpha$ (37) (Fig. 2). However, the interaction between the oestrogen signalling pathway and the BMP pathway and their implication in breast cancer still needs more exploration.

Several other factors and pathways have been indicated in the regulation of BMP expression and function. This includes the interrelationship between BMPs and other members of the TGF-ß (13), EGF (33), HGF and HGF receptors (38-40). BMPs may also have implications with other factors such as Tumour-associated trypsin inhibitor (TAT1) (41), ID-1 (17) and PTEN (42).

\section{The expression pattern of BMPs and BMP receptors in mammary gland and primary mammary tumours}

The aforementioned roles of BMPs and BMP receptors in breast cancer and in bone metastasis undoubtedly sparked substantial interest in examining the expression pattern of these molecules in clinical breast cancer. A few BMPs have been since investigated, however often with inconsistent results. BMP- 6 mRNA was detectable in breast carcinoma tissues, its level was reduced in breast carcinoma (18/44)

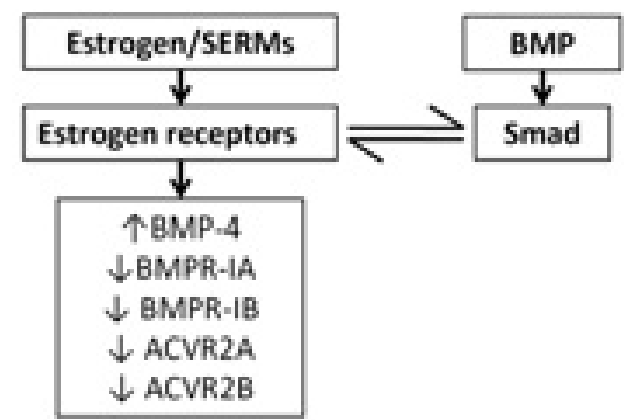

Figure 2. Crosstalk between oestrogen and BMP signalling in breast cancer cells.

compared with tumour-free resection margins. However, higher levels of BMP-6 mRNA were also found in 8 of the 44 patient samples in comparison with non-tumour margins (43). BMP-2 transcript was decreased in breast primary tumour, in contrast to that of activin- $\beta A$ and osteopontin $(\mathrm{OPN})$, which were elevated in these primary tumours (44). Decreased BMP-7 expression in primary tumours was associated with bone metastasis (27). Decreased expression of GDF-9a and BMP-12 was seen in breast cancer compared to matched background tissue and lower expression levels were associated with poor clinical outcome $(21,45)$. A more recent study from the host lab examined the expression of BMP-2 to BMP-7 in a breast cancer cohort using immunohistochemical staining and quantitative PCR. The results showed that BMP-2 and BMP-7 were decreased in breast cancer and correlated with poor prognosis (46).

In contrast to these findings, elevated expression of BMPs has been demonstrated in other studies. For example, BMP-7 was only seen in nuclei of breast cancer cells, but was not detectable in normal breast tissue using immunohistochemical staining (47). BMP-2 and BMP-4 were highly expressed in invasive breast cancer compared to the adjacent normal mammary tissue (16). BMP-4 and BMP-7 were elevated in breast cancer compared to normal breast tissue $(48,49)$. Upregulated BMP-7 expression in primary tumours may correlate with the disease-specific bone metastases of breast cancer (50). BMP-5 was highly expressed in breast cancer and the increasing expression correlated with poor prognosis (46).

Meanwhile, investigations into the expression patterns of BMP receptors and intracellular signalling molecules have also been conducted, but to a rather limited extent. Elevated expression of BMPR-IB was associated with high tumour grade, high tumour proliferation, cytogenetic instability and a poor prognosis in oestrogen receptor-positive carcinomas (51). This suggests that the expression of this type I receptor may associate with the ER status and is regulated by estrogen. The results from the host lab showed a decreased level of BMPR-1B in breast cancer, which was associated with poor prognosis (52).

Activation of the Smad pathway of BMPs (Smad1/5/8) and TGF- $\beta$ (Smad2) was revealed in nuclei of breast cancer cells in both primary tumours and bone metastases and similar involvements were also seen in an in vivo model. TGF- 33 and BMP-2 could promote motility and invasiveness of breast cancer cells (MDA-231-D) in vitro. Moreover, expression of 
Table I. BMP and BMP signalling in breast cancer.

\begin{tabular}{|c|c|c|c|c|c|c|c|}
\hline & \multicolumn{2}{|c|}{ Expression in breast cancer } & \multicolumn{3}{|c|}{ Functions in breast cancer cells } & \multicolumn{2}{|c|}{$\begin{array}{l}\text { Effect on } \\
\text { in vivo tumour }\end{array}$} \\
\hline & Primary tumour & Bone metastasis & Proliferation & Apoptosis & Motility & Primary & Bone \\
\hline BMP-2 & $\downarrow / \uparrow$ & & $\downarrow /-$ & $\downarrow / \uparrow$ & $\uparrow$ & $\uparrow$ & $\uparrow$ \\
\hline BMP-3 & $\downarrow$ & & & & & & \\
\hline BMP-4 & $\uparrow$ & & $\uparrow$ & & & & \\
\hline BMP-5 & $\uparrow$ & & & & & & \\
\hline BMP-6 & $\downarrow / \uparrow$ & & $\downarrow$ & $\downarrow$ & & & \\
\hline BMP-7 & $\downarrow / \uparrow$ & $\downarrow$ & $\downarrow / \uparrow$ & & $\uparrow$ & $\downarrow$ & $\downarrow$ \\
\hline GDF-9a & $\downarrow$ & & $\downarrow$ & & $\downarrow$ & & \\
\hline BMP-15 & $\downarrow$ & & & & & & \\
\hline BMPR-IA & & & & & $\uparrow$ & & $\uparrow$ \\
\hline BMPR-IB & $\downarrow / \uparrow$ & & $\downarrow$ & & & & \\
\hline BMPR-II & & & $\uparrow$ & & & & \\
\hline p-Smad-2,-3 & & $\uparrow$ & & & & & \\
\hline p-Smad $m,-1,-5,-8$ & & $\uparrow$ & & & & & \\
\hline Noggin & & & & & & - & $\downarrow$ \\
\hline Gremlin & $\uparrow$ & & & & & & \\
\hline
\end{tabular}

BMP and BMP signalling in breast cancer. $\downarrow$, stands for decrease or inhibit; $\uparrow$, stands for increase or promote; -, stands for no effect; blank represents unknown.

domain-negative receptors for TGF- 3 and/or BMPs in the MDA-231-D cells inhibited invasiveness in vitro and bone metastasis in the xenograft model. These results suggest that BMPs as well as TGF- $\beta$ promote invasion and bone metastasis of breast cancer (13).

In contrast to investigation into clinical breast cancer, studies on the expression of BMPs in breast cancer cell lines appear to be more consistent. Semi-quantitative PCR indicated that BMP-2 and BMP-3 but not BMP-4 and BMP-7, were present in MDA-MB-231 and MCF-7 cells. BMPR-1A, BMPR-1B and BMPR-2 were all detectable in both breast cancer cells at mRNA level. Both transcripts and protein of BMP-2 in MDA-MB-231 cells were decreased in exposure to radiation, whereas the level of BMP-2 in MCF-7 cells was not changed after radiation (3). This provided information for in vitro studies of BMPs in breast cancer.

Although the expression of specific BMPs, such as BMP-2, $-4,-6$ and -7 in breast cancer is still controversial, the aberrant expression of these BMPs and BMP receptors has been indicated in the development and progression of breast cancer (Table I). The aberrations in the BMP phenotype and signalling in breast cancer, may due to the ER status and self-adjustment by tumour cells themselves according to the needs for development and progression at different stages.

\section{BMPs and bone metastasis from breast cancer}

Both clinical and experimental studies suggest profound roles for BMPs in bone metastasis of breast cancer. Decreased expression of BMP-7 has been indicated in primary tumours in association with bone metastases. BMP-7 is able to inhibit the growth of breast cancer tumours at primary sites and in bone in vivo (27). Orthotropic implant of tumours with silk scaffolds which were coupled with bone morphogenetic protein-2 (BMP-2) and seeded with bone marrow stromal cells (BMSC), contributed to metastatic spread of breast cancer cells (53). These studies suggest that BMPs are involved in the bone metastasis of breast cancer. On the other hand, lack of BMP antagonists in breast cancer may contribute to the osteoblastic lesions of breast cancer. Conditioned medium (CM) from breast cancer cells (HT-39) could result in an up-regulation of bone sialoprotein mRNA expression in osteoprogenitor cells (MC3T3-E1 cells) and a promotion of their osteoblastic behaviour. This effect could be blocked by addition of Noggin, a BMP antagonist (54). A more recent study also demonstrated that lack of the noggin expression in both breast and prostate cancer cells was associated with osteoblastic activities in the bone metastases. Forced expression of Noggin in an osteo-inductive prostate cancer cell line (C4-2B) reduced in vivo osteoblastic responses induced by its intravenous xenografts, but had little or no influence on bone resorption and tumour growth (55). Unlike Noggin, another BMP antagonist, Gremlin, has been demonstrated to be overexpressed in some human cancers, including breast cancer (56). However, the roles that Gremlin and other BMP antagonists play in coordinating the osteoblastic and osteolytic activities in bone metastatic lesions are far from clear.

$\mathrm{CM}$ from breast cancer cells (MCF-7) or prostate cancer cells (LNCaP) could up-regulate osteopontin (OPN) in osteoblasts through the protein kinase $\mathrm{C}(\mathrm{PKC})$ pathway and mitogen-activated protein kinase (MAPK) pathway. This resulted in inhibition of proliferation and differentiation in osteoblastic cells (57). Another study showed CM from breast cancer (MCF-7) cell-induced apoptosis in preosteoblastic cells (FHSO-6) (58). 


\section{Perspectives and therapeutic potential}

Aberrant expression of BMPs and BMP signalling has been implicated in breast cancer and disease-specific bone metastasis. The expression of some BMPs in primary tumours may have predicting potential, such as that expression of BMP-7 may be associated with bone metastasis and decreasing levels of Noggin may indicate bone metastasis and more osteoblastic activites in bone lesions.

The more recent studies have demonstrated activation of BMP signalling in both breast primary tumours and bone metastases, which contribute to aggressiveness of tumour cells, and development of bone lesions. Lack of Noggin in both breast and prostate cancer cells correlates with their active osteoblastic feature. In the in vivo bone tumour model, Noggin, an antagonist of BMPs, has been shown to prevent bone metastasis by inhibiting both osteoblastic and osteolytic processes. These findings collectively indicate a promising therapeutic value for BMPs and their antagonists in the management of bone metastases.

BMPs and their signalling play a profound role in the development, progression and metastasis of breast cancer. Further investigation will elucidate the mechanisms underlying the involvement of BMPs in breast cancer. It will expand current understanding for the pathogenesis of breast cancer and may provide clues for developing novel therapies in managing advanced diseases.

\section{Acknowledgements}

The authors would like to thank the Cancer Research of Wales for their support.

\section{References}

1. Ye L, Lewis-Russell JM, Kyanaston HG and Jiang WG: Bone morphogenetic proteins and their receptor signaling in prostate cancer. Histol Histopathol 22: 1129-1147, 2007.

2. Du J, Yang S, Wang Z, Zhai C, Yuan W, Lei R, Zhang J and Zhu T: Bone morphogenetic protein 6 inhibit stress-induced breast cancer cells apoptosis via both Smad and p38 pathways. J Cell Biochem 103: 1584-1597, 2008.

3. Arnold SF, Tims E and McGrath BE: Identification of bone morphogenetic proteins and their receptors in human breast cancer cell lines: importance of BMP2. Cytokine 11: 1031-1037, 1999.

4. Montesano R, Sarkozi R and Schramek H: Bone morphogenetic protein-4 strongly potentiates growth factor-induced proliferation of mammary epithelial cells. Biochem Biophys Res Commun 374: $164-168,2008$

5. Alarmo EL, Parssinen J, Ketolainen JM, Savinainen K, Karhu R and Kallioniemi A: BMP7 influences proliferation, migration, and invasion of breast cancer cells. Cancer Lett 275: 35-43, 2009.

6. Ghosh-Choudhury N, Ghosh-Choudhury G, Celeste A, Ghosh PM, Moyer M, Abboud SL and Kreisberg J: Bone morphogenetic protein-2 induces cyclin kinase inhibitor p21 and hypophosphorylation of retinoblastoma protein in estradiol-treated MCF-7 human breast cancer cells. Biochim Biophys Acta 1497: 186-196, 2000.

7. Ghosh-Choudhury N, Woodruff K, Qi W, Celeste A, Abboud SL and Ghosh Choudhury G: Bone morphogenetic protein-2 blocks MDA MB 231 human breast cancer cell proliferation by inhibiting cyclin-dependent kinase-mediated retinoblastoma protein phosphorylation. Biochem Biophys Res Commun 272: 705-711, 2000 .

8. Soda H, Raymond E, Sharma S, Lawrence R, Cerna C, Gomez L, Timony GA, Von Hoff DD and Izbicka E: Antiproliferative effects of recombinant human bone morphogenetic protein-2 on human tumor colony-forming units. Anticancer Drugs 9: 327-331, 1998.
9. Pouliot F and Labrie C: Role of Smad1 and Smad4 proteins in the induction of p21WAF1, Cip1 during bone morphogenetic protein-induced growth arrest in human breast cancer cells. J Endocrinol 172: 187-198, 2002.

10. Takahashi M, Otsuka F, Miyoshi T, Otani H, Goto J, Yamashita M, Ogura T, Makino H and Doihara H: Bone morphogenetic protein 6 (BMP6) and BMP7 inhibit estrogen-induced proliferation of breast cancer cells by suppressing p38 mitogen-activated protein kinase activation. J Endocrinol 199: 445-455, 2008.

11. Pouliot F, Blais A and Labrie C: Overexpression of a dominant negative type II bone morphogenetic protein receptor inhibits the growth of human breast cancer cells. Cancer Res 63: 277-281, 2003.

12. Dumont $\mathrm{N}$ and Arteaga CL: A kinase-inactive type II TGFbeta receptor impairs BMP signaling in human breast cancer cells. Biochem Biophys Res Commun 301: 108-112, 2003.

13. Katsuno Y, Hanyu A, Kanda H, Ishikawa Y, Akiyama F, Iwase T, Ogata E, Ehata S, Miyazono K and Imamura T: Bone morphogenetic protein signaling enhances invasion and bone metastasis of breast cancer cells through Smad pathway. Oncogene 27: 6322-6333, 2008.

14. Bokobza SM, Ye L, Kynaston HE, Mansel RE and Jiang WG: Reduced expression of BMPR-IB correlates with poor prognosis and increased proliferation of breast cancer cells. Cancer Genomics Proteomics 6: 101-108, 2009.

15. Steinert S, Kroll TC, Taubert I, Pusch L, Hortschansky P, Hoffken K, Wolfl S and Clement JH: Differential expression of cancer-related genes by single and permanent exposure to bone morphogenetic protein 2. J Cancer Res Clin Oncol 134: 1237-1245, 2008.

16. Raida M, Clement JH, Ameri K, Han C, Leek RD and Harris AL: Expression of bone morphogenetic protein 2 in breast cancer cells inhibits hypoxic cell death. Int J Oncol 26: 1465-1470, 2005.

17. Clement JH, Marr N, Meissner A, Schwalbe M, Sebald W, Kliche KO, Hoffken K and Wolfl S: Bone morphogenetic protein 2 (BMP-2) induces sequential changes of Id gene expression in the breast cancer cell line MCF-7. J Cancer Res Clin Oncol 126: 271-279, 2000.

18. Clement JH, Raida M, Sanger J, Bicknell R, Liu J, Naumann A, Geyer A, Waldau A, Hortschansky P, Schmidt A, Hoffken K, Wolft S and Harris AL: Bone morphogenetic protein 2 (BMP-2) induces in vitro invasion and in vivo hormone independent growth of breast carcinoma cells. Int J Oncol 27: 401-407, 2005.

19. Scherberich A, Tucker RP, Degen M, Brown-Luedi M, Andres AC and Chiquet-Ehrismann R: Tenascin-W is found in malignant mammary tumors, promotes alpha8 integrin-dependent motility and requires p38MAPK activity for BMP- 2 and TNFalpha induced expression in vitro. Oncogene 24: 1525-1532, 2005.

20. Gautschi O, Tepper CG, Purnell PR, Izumiya Y, Evans CP, Green TP, Desprez PY, Lara PN, Gandara DR, Mack PC and Kung HJ: Regulation of Id1 expression by SRC: implications for targeting of the bone morphogenetic protein pathway in cancer. Cancer Res 68: 2250-2258, 2008.

21. Hanavadi S, Martin TA, Watkins G, Mansel RE and Jiang WG: The role of growth differentiation factor-9 (GDF-9) and its analog, GDF-9b/BMP-15, in human breast cancer. Ann Surg Oncol 14: 2159-2166, 2007.

22. Johansson N, Saarialho-Kere U, Airola K, Herva R, Nissinen L, Westermarck J, Vuorio E, Heino J and Kahari VM: Collagenase-3 (MMP-13) is expressed by hypertrophic chondrocytes, periosteal cells, and osteoblasts during human fetal bone development. Dev Dyn 208: 387-397, 1997.

23. Montesano R: Bone morphogenetic protein-4 abrogates lumen formation by mammary epithelial cells and promotes invasive growth. Biochem Biophys Res Commun 353: 817-822, 2007.

24. Yang S, Zhong C, Frenkel B, Reddi AH and Roy-Burman P: Diverse biological effect and Smad signaling of bone morphogenetic protein 7 in prostate tumor cells. Cancer Res 65: 5769-5777, 2005.

25. Piek E, Moustakas A, Kurisaki A, Heldin $\mathrm{CH}$ and ten Dijke P: TGF-(beta) type I receptor/ALK-5 and Smad proteins mediate epithelial to mesenchymal transdifferentiation in NMuMG breast epithelial cells. J Cell Sci 112 (Pt 24): 4557-4568, 1999.

26. Yang S, Du J, Wang Z, Yuan W, Qiao Y, Zhang M, Zhang J, Gao S, Yin J, Sun B and Zhu T: BMP-6 promotes E-cadherin expression through repressing deltaEF1 in breast cancer cells. BMC Cancer 7: 211, 2007. 
27. Buijs JT, Henriquez NV, van Overveld PG, van der Horst G, Que I, Schwaninger R, Rentsch C, Ten Dijke P, Cleton-Jansen AM, Driouch K, Lidereau R, Bachelier R, Vukicevic S, Clezardin P, Papapoulos SE, Cecchini MG, Lowik CW and van der Pluijm G: Bone morphogenetic protein 7 in the development and treatment of bone metastases from breast cancer. Cancer Res 67: 8742-8751, 2007.

28. Mori S, Yoshikawa H, Hashimoto J, Ueda T, Funai H, Kato M and Takaoka K: Antiangiogenic agent (TNP-470) inhibition of ectopic bone formation induced by bone morphogenetic protein-2. Bone 22: 99-105, 1998.

29. Yamashita H, Shimizu A, Kato M, Nishitoh H, Ichijo H, Hanyu A, Morita I, Kimura M, Makishima F and Miyazono K: Growth/ differentiation factor-5 induces angiogenesis in vivo. Exp Cell Res 235: 218-226, 1997

30. Dai J, Kitagawa Y, Zhang J, Yao Z, Mizokami A, Cheng S, Nor J, McCauley LK, Taichman RS and Keller ET: Vascular endothelial growth factor contributes to the prostate cancer-induced osteoblast differentiation mediated by bone morphogenetic protein. Cancer Res 64: 994-999, 2004.

31. Deckers MM, van Bezooijen RL, van der Horst G, Hoogendam J, van Der Bent C, Papapoulos SE and Lowik CW: Bone morphogenetic proteins stimulate angiogenesis through osteoblastderived vascular endothelial growth factor A. Endocrinology 143: 1545-1553, 2002

32. Raida M, Clement JH, Leek RD, Ameri K, Bicknell R, Niederwieser D and Harris AL: Bone morphogenetic protein 2 (BMP-2) and induction of tumor angiogenesis. J Cancer Res Clin Oncol 131: 741-750, 2005

33. Schwalbe M, Sanger J, Eggers R, Naumann A, Schmidt A Hoffken $\mathrm{K}$ and Clement JH: Differential expression and regulation of bone morphogenetic protein 7 in breast cancer. Int J Oncol 23: 89-95, 2003.

34. Zhang M, Wang Q, Yuan W, Yang S, Wang X, Yan JD, Du J, Yin J, Gao SY, Sun BC and Zhu TH: Epigenetic regulation of bone morphogenetic protein- 6 gene expression in breast cancer cells. J Steroid Biochem Mol Biol 105: 91-97, 2007.

35. van den Wijngaard A, Mulder WR, Dijkema R, Boersma CJ, Mosselman S, van Zoelen EJ and Olijve W: Antiestrogens specifically up-regulate bone morphogenetic protein-4 promoter activity in human osteoblastic cells. Mol Endocrinol 14: 623$633,2000$.

36. Yamamoto T, Saatcioglu F and Matsuda T: Cross-talk between bone morphogenic proteins and estrogen receptor signaling. Endocrinology 143: 2635-2642, 2002.

37. Wu L, Wu Y, Gathings B, Wan M, Li X, Grizzle W, Liu Z, Lu C, Mao Z and Cao X: Smad4 as a transcription corepressor for estrogen receptor alpha. J Biol Chem 278: 15192-15200, 2003.

38. Imai $Y$, Terai H, Nomura-Furuwatari C, Mizuno S, Matsumoto K, Nakamura $T$ and Takaoka K: Hepatocyte growth factor contributes to fracture repair by upregulating the expression of BMP receptors. J Bone Miner Res 20: 1723-1730, 2005.

39. Ye L, Lewis-Russell JM, Davies G, Sanders AJ, Kynaston H and Jiang WG: Hepatocyte growth factor up-regulates the expression of the bone morphogenetic protein (BMP) receptors, BMPR-IB and BMPR-II, in human prostate cancer cells. Int J Oncol 30: 521-529, 2007.

40. Ye L, Lewis-Russell JM, Sanders AJ, Kynaston H and Jiang WG: HGF/SF up-regulates the expression of bone morphogenetic protein 7 in prostate cancer cells. Urol Oncol 26: 190-197, 2008.

41. Gouyer V, Fontaine D, Dumont P, de Wever O, FontayneDevaud H, Leteurtre E, Truant S, Delacour D, Drobecq H, Kerckaert JP, de Launoit Y, Bracke M, Gespach C, Desseyn JL and Huet G: Autocrine induction of invasion and metastasis by tumor-associated trypsin inhibitor in human colon cancer cells. Oncogene 27: 4024-4033, 2008.

42. Waite KA and Eng C: BMP2 exposure results in decreased PTEN protein degradation and increased PTEN levels. Hum Mol Genet 12: 679-684, 2003.
43. Clement JH, Sanger J and Hoffken K: Expression of bone morphogenetic protein 6 in normal mammary tissue and breast cancer cell lines and its regulation by epidermal growth factor. Int J Cancer 80: 250-256, 1999.

44. Reinholz MM, Iturria SJ, Ingle JN and Roche PC: Differential gene expression of TGF-beta family members and osteopontin in breast tumor tissue: analysis by real-time quantitative PCR. Breast Cancer Res Treat 74: 255-269, 2002.

45. Li J, Ye L, Parr C, Douglas-Jones A, Kyanaston HG, Mansel RE and Jiang WG: The aberrant expression of bone morphogenetic protein 12 (BMP-12) in human breast cancer and its potential prognostic value. Gene Ther Mol Biol 13: 186-193, 2009.

46. Davies SR, Watkins G, Douglas-Jones A, Mansel RE and Jiang WG: Bone morphogenetic proteins 1 to 7 in human breast cancer, expression pattern and clinical/prognostic relevance. J Exp Ther Oncol 7: 327-338, 2008.

47. Bobinac D, Maric I, Zoricic S, Spanjol J, Dordevic G, Mustac E and Fuckar Z: Expression of bone morphogenetic proteins in human metastatic prostate and breast cancer. Croat Med J 46: 389-396, 2005.

48. Alarmo EL, Rauta J, Kauraniemi P, Karhu R, Kuukasjarvi T and Kallioniemi A: Bone morphogenetic protein 7 is widely overexpressed in primary breast cancer. Genes Chromosomes Cancer 45: 411-419, 2006.

49. Alarmo EL, Kuukasjarvi T, Karhu R and Kallioniemi A: A comprehensive expression survey of bone morphogenetic proteins in breast cancer highlights the importance of BMP4 and BMP7. Breast Cancer Res Treat 103: 239-246, 2007.

50. Alarmo EL, Korhonen T, Kuukasjarvi T, Huhtala H, Holli K and Kallioniemi A: Bone morphogenetic protein 7 expression associates with bone metastasis in breast carcinomas. Ann Oncol 19: 308-314, 2008.

51. Helms MW, Packeisen J, August C, Schittek B, Boecker W, Brandt $\mathrm{BH}$ and Buerger $\mathrm{H}$ : First evidence supporting a potential role for the BMP/SMAD pathway in the progression of oestrogen receptor-positive breast cancer. J Pathol 206: 366-376, 2005.

52. Bokobza S, Ye L, Kynaston H, Mansel RE and Jiang WG: Reduced expression of BMPR-IB correlates with poor prognosis and increased proliferation of breast cancer cells. Cancer Genomics Proteomics (In press).

53. Moreau JE, Anderson K, Mauney JR, Nguyen T, Kaplan DL and Rosenblatt M: Tissue-engineered bone serves as a target for metastasis of human breast cancer in a mouse model. Cancer Res 67: 10304-10308, 2007.

54. Bunyaratavej P, Hullinger TG and Somerman MJ: Bone morphogenetic proteins secreted by breast cancer cells upregulate bone sialoprotein expression in preosteoblast cells. Exp Cell Res 260: 324-333, 2000.

55. Schwaninger R, Rentsch CA, Wetterwald A, van der Horst G, van Bezooijen RL, van der Pluijm G, Lowik CW, Ackermann K, Pyerin W, Hamdy FC, Thalmann GN and Cecchini MG: Lack of noggin expression by cancer cells is a determinant of the osteoblast response in bone metastases. Am J Pathol 170: 160-175, 2007.

56. Namkoong H, Shin SM, Kim HK, Ha SA, Cho GW, Hur SY, Kim TE and Kim JW: The bone morphogenetic protein antagonist gremlin 1 is overexpressed in human cancers and interacts with YWHAH protein. BMC Cancer 6: 74, 2006.

57. Hullinger TG, Taichman RS, Linseman DA and Somerman MJ: Secretory products from PC-3 and MCF-7 tumor cell lines upregulate osteopontin in MC3T3-E1 cells. J Cell Biochem 78: 607-616, 2000

58. Fromigue O, Kheddoumi N, Lomri A, Marie PJ and Body JJ: Breast cancer cells release factors that induced apoptosis in human bone marrow stromal cells. J Bone Miner Res 16: 1600-1610, 2001. 